\title{
Optimal Scheduling of Flowshop Batch Process for Zero-Wait and No Intermediate Storage Transfer Policy
}

\author{
H. Abdel Samad \\ Teaching Assistant \\ Chemical \\ Engineering \\ Department- High \\ Institute of \\ Engineering \\ Shorouk City
}

\author{
H. Moselhy \\ Associated Professor \\ Chemical \\ Engineering \\ Department- High \\ Institute of \\ Engineering \\ Shorouk City
}

\author{
S. Aly \\ Professor \\ Chemical and \\ Petroleum Refining \\ Engineering \\ Department \\ Suez University
}

\author{
M. E. Awad \\ Associated Professor \\ Chemical and \\ Petroleum Refining \\ Engineering \\ Department \\ Suez University
}

\begin{abstract}
The scheduling zero-wait (ZW) and no intermediate storage transfer (NIS) policy of multi-product batch processes in order to produce a number of low volume high value-added chemical products because of its economic impact.

It involves various parameters such as makespan (completion time) which is recognized as one of the important design parameter as it helps to decide for the best scheduling design and normally used as the main parameter for selecting the optimal production sequence which involves various parameters such as batch process recipes, sequence of production and transfer policy for product intermediates.

In this paper, we present a development, solution and computational performance evaluation of optimal scheduling for multiproduct batch process with two commonly used transfer policies namely zero wait (ZW) and no intermediate storage (NIS) by using computer program language software (Java) which simplify and improve the determination of Makespan and select the optimum sequence due to the minimum Makespan.
\end{abstract}

\section{Keywords}

Scheduling, Batch processes, Makespan, Production Sequence, Zero Wait, No Intermediate Storage.

\section{INTRODUCTION}

Batch processes play an important role in producing low volume and high value-added chemical and biochemical products. In batch process operations; production scheduling is to determine the most efficient way to produce a set of desired products in a given amount of time while utilizing a set of limited resources, some processing equipment, and processing recipes. The tasks to be scheduled usually take place in multiproduct batch plants, in which a wide variety of different products can be manufactured via the same recipe or different recipes by sharing limited resources, such as equipment, material, time, and utilities.

The different types of interstage storage policies which have frequently been studied are unlimited intermediate storage (UIS), finite intermediate storage (FIS), no intermediate storage (NIS), zero wait (ZW), mixed intermediate storages (MIS) policies and process intermediate storages(PIS). Sometimes, the intermediate product produced in a batch process is not stable and cannot wait and must be transferred immediately to the next stage. The zero-wait formulation with completion times for scheduling problem in batch processes is first presented by Ku and Karimi [11], but this model did not include the setup times. Considering setup times have significant influent on batch operations, complex scheduling descriptions with transfer and setup times under ZW Policy are also studied by Jung, Lee, Yang, and Lee[8], Kim, Jung, and Lee [10], Lee et al. [15], Shafeeq et al. [20] where they proposed a matrix-based completion algorithm for ZWSP in multiproduct batch processes. Recently, M-G Dong et al. [16] proposed a novel hybrid permutation based differential evolution for zero-wait scheduling problems of batch plant with high quality solution in short computational time. Most of the currently available methods for determining makespan are based on complex mathematical programming techniques mostly use of mathematical methods such as mixed integer linear programming (MILP) and mixed integer nonlinear programming (MINLP) in all the formulations for determining minimum makespan for batch processes (Jung et al., [8]; Kim et al.,[10]; Moon et al., [17]; Biegler et al., [1]; Das et al., [4]; Caraffa et al., [21]; Burkard et al., [3]; Dupont and DhaenensFlipo, [14]; Lee et al., [15]; Ryu and Pistikopoulos Efstratios, [19]. Although it is capable of providing the optimal solution, but it doesn't provide other near optimal solutions from which a designer should have a flexibility to choose, especially when there are subjective constraints that need to be considered. Also, they require good understanding on formulating the batch scheduling problem.

In this paper the scheduling zero-wait (ZW) and no intermediate storage (NIS) transfer policy of multi-product batch processes involves various parameters of which makespan is normally used as the main parameter for selecting the optimal production sequence, at firstly uses of traditional Gantt chart method which is simple and could also generate design options that are near optimal based on makespan calculation and focuses on using computer programming language (Java) which simplify and improve the determination of Makespan for each sequence and select the optimal sequence due to the minimum Makespan.

\section{OPTIMUM BATCH PRODUCTION SEQUENCE}

The optimum production sequences for batch processes depends on the arrangements of products sequence which gives minimum completion time (Makespan) where the possible number of production sequences can be calculated as possible production sequences as stated by Shafeeq et al. [20] $p(n)=n$ !, Where $n$ is the number of products. For example in case of scheduling four product the possible production sequence $\mathrm{P}(4)$ $=4 !=24$ and $\mathrm{P}(5)=5 !=120$ production sequence. 


\section{GANTT CHART}

Commonly, It is used in project management and it is one of the most popular and useful ways of showing activities (tasks or events) displayed against time. It is most commonly used for tracking project schedules. For this it is useful to be able to show additional information about the various tasks or phases of the project. Typically, tasks are shown on the vertical axis, and the project time span is represented on the horizontal axis. Each task has a corresponding bar that shows the time span required for that task. The bar can be filled in to show the percentage of the task that has been completed. Gantt charts also indicate dependences, those tasks that are dependent upon other tasks.

\section{MATHEMATICAL MODEL DESCRIPTION}

A general mathematical model to calculate the total completion time (makespan) of batch process with number of products " N " and number of stages " $\mathrm{M}$ " based on matrix formulation and (Fig.1) and (Fig.2) describes the flowchart of programming language (Java) used for description the calculation and estimation of optimal sequence for any number of products must be schedule and by giving the values of makespan of each sequence with its idle times and holding time in case of (NIS) transfer policy and also select the optimum sequence for batch process.

For example if we schedule four product A, B , C and D in three stages $S_{1}, S_{2}$ and $S_{3}$. So, according to the matrix approach as shown in table 1 and table 2 where at first arrangement the products and stages of batch process as the form of matrix \{ rows \& column $\}$ at which rows refers to products and column refers to units or stages \{Amir Shafeeq, et al .[20]\}.

\subsection{Zero Wait (ZW) Transfer Policy}

$$
\begin{array}{ll}
\mathrm{V}_{\mathrm{i}, 2}=\mathrm{T}_{\mathrm{i}+1,1}-\mathrm{T}_{\mathrm{i}, 2} & \mathrm{i}=1 \ldots \mathrm{N}-1 \\
\mathrm{~V}_{\mathrm{i}, \mathrm{j}+1}=\left(\mathrm{V}_{\mathrm{i}, \mathrm{j}}+\mathrm{T}_{\mathrm{i}+1, j}\right)-\mathrm{T}_{\mathrm{i}, \mathrm{j}+1} & \mathrm{i}=1 \ldots \mathrm{N}-1 \\
\mathrm{~V}_{\mathrm{i}, \mathrm{j}}=\left(\mathrm{V}_{\mathrm{i}, \mathrm{j}+1}-\mathrm{T}_{\mathrm{i}+1, \mathrm{j}}\right)+\mathrm{T}_{\mathrm{i}, \mathrm{j}+1} & \mathrm{~J}=2 \ldots \mathrm{M}-1 \\
& \mathrm{i}=1 \ldots \mathrm{N}-1 \\
& \mathrm{~J}=2 . . \mathrm{M}-1
\end{array}
$$

makespan $=\sum_{j=1}^{\mathrm{m}} \mathrm{T}_{\mathrm{i}, \mathrm{j}}+\sum_{i=1}^{n} T_{i, m}+\sum_{i=1}^{n-1} V_{i, m}$

\subsection{No Intermediate Storage (NIS) Transfer} Policy:

$$
\begin{array}{ll}
\mathrm{V}_{\mathrm{i}, 1}=0 \& \mathrm{H}_{\mathrm{i}, \mathrm{m}}=0 & \mathrm{i}=1 \ldots . \mathrm{N}-1 \\
\mathrm{~V}_{\mathrm{i}, \mathrm{j}+1}=\left(\mathrm{V}_{1, j}+\mathrm{T}_{2, j}\right)-\mathrm{T}_{1, \mathrm{j}+1} & \mathrm{~J}=2 \ldots . \mathrm{M}-1 \\
\mathrm{H}_{\mathrm{i}, \mathrm{j}-1}=-\mathrm{V}_{\mathrm{i}, \mathrm{j}} & \mathrm{i}=1 \ldots . . \mathrm{N}-1 \\
\mathrm{~V}_{\mathrm{i}, \mathrm{j}+1}=\left(\mathrm{V}_{\mathrm{i}, \mathrm{j}}+\mathrm{T}_{\mathrm{i}+1, \mathrm{j}}\right)-\left(\mathrm{T}_{\mathrm{i}, \mathrm{j}+1}+\mathrm{H}_{\mathrm{i}-1, \mathrm{j}+1}\right) & \mathrm{J}=1 \ldots . \mathrm{M}-1 \\
& \mathrm{~J}=1 \ldots . \mathrm{N}-1
\end{array}
$$

\section{PROBLEM STATEMENT}

The production task to produce one batch of each product where the completion time calculation is performed for zero wait transfer policy (ZW) as we presented in example1 and example 2 where the intermediate products is not stable and must be transferred to next stage. Also, the completion time calculation (Makespan) evaluation is performed for flowshop (multiproduct) batch process using No Intermediate Storage (NIS) policy as we presented in example 3 where the intermediate is allowed to wait in the same unit from which it is produced until the next unit is available. The time of waiting in the unit known as holding time for which the succeeding product has to stay in the same unit till the next unit has finished processing the preceding product.

In the two types of transfer policy firstly, Gantt chart method is used to determine the production sequence on various stages of feasible sequence for batch process for the two types. Later, computer programming Java language applied to generate all possible sequence with the value of makespan for each sequence and determine minimum makespan as the optimal sequence.

\section{EXAMPLES}

The proposed method (Java programming language) will be examined using three case studies reported in literature for comparison.

\subsection{Example 1}

Four products namely $\mathrm{P}_{1}, \mathrm{P}_{2}, \mathrm{P}_{3}$ and $\mathrm{P}_{4}$ based on four unit operation $S_{1}, S_{2}, S_{3}$, and $S_{4}$ are produced in a batch process and shown in table 3 \{Ming et al, [16]\}.

Gantt chart observed several possible paths (Fig.3) that can estimate of makespan and also observed that there is some discontinuity path which refer to the idle time between stages (Table 4) which must estimate this value of idle time before determining of makespan due to the fact of accordance with zero-wait transfer policy so, in determination of makespan it is important to estimate the value of idle time between stages.

It is clear that, from observation of Gantt chart (Fig.3) there are some of possible paths that indicate the makespan of batch process which is illustrated in example 1.

One of these paths by taking the sum of $\mathrm{P}_{1} \mathrm{~S}_{1}, \mathrm{P}_{1} \mathrm{~S}_{2}, \mathrm{P}_{1} \mathrm{~S}_{3}, \mathrm{P}_{1} \mathrm{~S}_{4}$, $\mathrm{P}_{2} \mathrm{~S}_{4}, \mathrm{P}_{3} \mathrm{~S}_{4}$ and $\mathrm{P}_{4} \mathrm{~S}_{4}$, and also must include the idle time between $\mathrm{P}_{1} \mathrm{~S}_{4}$ and $\mathrm{P}_{2} \mathrm{~S}_{4}$ these idle time are due to the last stage of first product $\left(\mathrm{P}_{1}\right)$ finishes before the second product $\left(\mathrm{P}_{2}\right)$ in last stage begins. Also, idle time between $\mathrm{P}_{2} \mathrm{~S}_{4}, \mathrm{P}_{3} \mathrm{~S}_{4}$ which similarly, the second product $\left(\mathrm{P}_{2}\right)$ in the last stage finishes before the last stage of third product $\left(\mathrm{p}_{3}\right)$ begins and the idle time between $\mathrm{P}_{3} \mathrm{~S}_{4}, \mathrm{P}_{4} \mathrm{~S}_{4}$ also, means the third product $\left(\mathrm{P}_{3}\right)$ in last stag finishes before the last stage of the fourth product $\left(\mathrm{P}_{4}\right)$ begins.

Makespan $=[14+45+49+37+46+30+20]+[2+17+0]=260$

hr.

The other possible path to calculate the makespan is the sum of $\mathrm{P}_{1} \mathrm{~S}_{1}, \mathrm{P}_{2} \mathrm{~S}_{1}, \mathrm{P}_{3} \mathrm{~S}_{1}, \mathrm{P}_{3} \mathrm{~S}_{2}, \mathrm{P}_{3} \mathrm{~S}_{2}, \mathrm{P}_{3} \mathrm{~S}_{4}$ and $\mathrm{P}_{4} \mathrm{~S}_{4}$ and also must include the idle time between $\mathrm{P}_{1} \mathrm{~S}_{1}$ and $\mathrm{P}_{2} \mathrm{~S}_{1}$ between $\mathrm{P}_{3} \mathrm{~S}_{4}$ and $\mathrm{P}_{4} \mathrm{~S}_{4}$.

Makespan $=[14+36+29+45+30+19+20]+[46+0+21]=260$ hr.

It is clear from calculation of Makespan for any possible path of production sequences is to be the same value. i.e. in production sequence $\left[\mathrm{P}_{1}-\mathrm{P}_{2}-\mathrm{P}_{3}-\mathrm{P}_{4}\right.$, $]$ the Makespan calculations appears the same $(260 \mathrm{hr})$ this refer to all product must be follow the same sequence on all stages, also this offers flexibility to choose any path for calculation for any number of products and stages. 
The summary of results of the proposed method is shown in table 5, which confirmed with results obtained and which ensures our strategy and (Fig.4) represented the Gantt chart for optimal sequence $\left(\mathrm{P}_{2-} \mathrm{P}_{1-} \mathrm{P}_{3-} \mathrm{P}_{4}\right)$. Also, table 6 stated the value of idle time between stages for optimal sequence.

\subsection{Example 2}

Batch process producing six products in the sequence of product $\mathrm{A}$ followed by product $\mathrm{B}$ then product $\mathrm{C}$, then product $\mathrm{D}$, then product $\mathrm{E}$, and finally $\mathrm{F}$ using four stages operation namely $, \mathrm{S}_{1}, \mathrm{~S}_{2}, \mathrm{~S}_{3}$, and $\mathrm{S}_{4}$ which shown in table 8 \{D.B.Birewar et al, [ 2]\}.

From observation of Gantt chart (Fig. 5) there are some of possible paths that indicates the makespan of batch process illustrate in example 2. From observation to chart it is clear that, it must estimate the value of idle time between stages which presented in table 9 before determining of makespan due to zero-wait transfer policy (ZW).

One of these paths by taking the sum of $\mathrm{AS}_{1}, \mathrm{AS}_{2}, \mathrm{AS}_{3}, \mathrm{AS}_{4}$, $\mathrm{BS}_{4}, \mathrm{CS}_{4}, \mathrm{DS}_{4}, \mathrm{ES}_{4}$ and $\mathrm{FS}_{4}$, and which must include the idle time between $\mathrm{BS}_{4}$ and $\mathrm{CS}_{4}, \mathrm{CS}_{4}$ and $\mathrm{DS}_{4}, \mathrm{ES}_{4}$ and $\mathrm{FS}_{4}$.

Makespan $=10+20+5+30+10+5+10+15+10+6+14+6=141 \mathrm{hr}$ Also, from observations of Gantt chart for all possible paths (sequence) the value of makespan would be the same value which equal $141 \mathrm{hr}$ for any sequence selected. As we presented in section 2 \{optimum sequence\} to estimate the possible number of production sequences at which can be calculated as possible production sequences $\mathrm{p}(\mathrm{n})=\mathrm{n}$ ! So for the current case study which scheduling six product, the possible production sequence $P(6)=6 !=720$ production sequence, the computational result will be difficult to been shown in this section so, in table 10 we will present the summary of runs of computational results for current example.

\subsection{Example 3}

Four products in the sequence of product $\mathrm{A}$ followed by product $\mathrm{B}$ then product $\mathrm{C}$, and finally $\mathrm{D}$ using Six stages operation namely, $\mathrm{S}_{2}, \mathrm{~S}_{3}, \mathrm{~S}_{4}, \mathrm{~S}_{5}$ and $\mathrm{S}_{6}$ which shown in table 14 $\{$ J.H.Jung et al,[8]\}.

It is observed from Gantt chart (Fig.8) there another variable \{Shaded area\} which known as holding time which is in addition to the idle time between units according to the fact of accordance proposed policy which must estimate this value of idle and holding time between stages before determining of makespan.

Also, from Gantt chart observation there are some of possible paths that indicate the makespan of batch process illustrate in the current example. one of these paths by taking the sum of $\mathrm{AS}_{1}, \mathrm{AS}_{2}, \mathrm{AS}_{3}, \mathrm{AS}_{4}, \mathrm{AS}_{5}, \mathrm{AS}_{6}, \mathrm{BS}_{6}, \mathrm{CS}_{6}$ and $\mathrm{DS}_{6}$, and also must include the idle time between $\mathrm{AS}_{6}$ and $\mathrm{BS}_{6}, \mathrm{BS}_{6}$ and $\mathrm{P}_{3} \mathrm{~S}_{6}$, $\mathrm{P}_{3} \mathrm{~S}_{6}$ and $\mathrm{P}_{4} \mathrm{~S}_{6}$

Makespan $=10+15+20+12+8+11+13+9+4+[0+0+8]=110$ hr.

The second possible path to calculate the makespan by taking the sum of $\mathrm{AS}_{1}, \mathrm{BS}_{1}, \mathrm{BS}_{2}, \mathrm{BS}_{3}, \mathrm{BS}_{4}, \mathrm{BS}_{5}, \mathrm{BS}_{6}, \mathrm{CS}_{6}$ and $\mathrm{DS}_{6}$, and also must include the idle time between $\mathrm{AS}_{1}$ and $\mathrm{BS}_{1}, \mathrm{BS}_{6}$ and $\mathrm{CS}_{6}, \mathrm{CS}_{6}$ and $\mathrm{DS}_{6}$ and also must include the holding time of product "B" in $\mathrm{S}_{2}$.

Makespan $=10+15+8+12+10+9+13+9+4+[0+0+8]+12=110$ hr.

Also, from observations of Gantt chart for all another possible paths the value of makespan would be the same value which is equal $=110 \mathrm{hr}$.

Table 1. Products and stages arrangement of $\mathrm{ZW}$ transfer policy

\begin{tabular}{cccc}
\hline Products / Stages & $\mathbf{S}_{\mathbf{1}}$ & $\mathbf{S}_{\mathbf{2}}$ & $\mathbf{S}_{\mathbf{3}}$ \\
\hline $\mathbf{A}$ & $\mathrm{T}_{\mathrm{A}} \mathrm{S}_{1}$ & $\mathrm{~T}_{\mathrm{A}} \mathrm{S}_{2}$ & $\mathrm{~T}_{\mathrm{A}} \mathrm{S}_{3}$ \\
& $\mathrm{~V}_{1,1}$ & $\mathrm{~V}_{1,2}$ & $\mathrm{~V}_{1,3}$ \\
$\mathbf{B}$ & $\mathrm{T}_{\mathrm{B}} \mathrm{S}_{1}$ & $\mathrm{~T}_{\mathrm{B}} \mathrm{S}_{2}$ & $\mathrm{~T}_{\mathrm{B}} \mathrm{S}_{3}$ \\
& $\mathrm{~V}_{2,1}$ & $\mathrm{~V}_{2,2}$ & $\mathrm{~V}_{2,3}$ \\
$\mathbf{C}$ & $\mathrm{T}_{\mathrm{C}} \mathrm{S}_{1}$ & $\mathrm{~T}_{\mathrm{C}} \mathrm{S}_{2}$ & $\mathrm{~T}_{\mathrm{C}} \mathrm{S}_{3}$ \\
& $\mathrm{~V}_{3,1}$ & $\mathrm{~V}_{3,2}$ & $\mathrm{~V}_{3,3}$ \\
D & $\mathrm{T}_{\mathrm{D}} \mathrm{S}_{1}$ & $\mathrm{~T}_{\mathrm{D}} \mathrm{S}_{2}$ & $\mathrm{~T}_{\mathrm{D}} \mathrm{S}_{3}$ \\
\hline
\end{tabular}

where $\mathrm{TiS}_{\mathrm{n}}$ : processing time of product in stage

$\mathrm{V}_{\mathrm{n}, \mathrm{m}}$ : idle time of products between stage

Table 2. Products and stages arrangement of NIS transfer policy

\begin{tabular}{|c|c|c|c|c|c|}
\hline Products /Stages & $S_{1}$ & & S2 & & $\mathbf{S}_{3}$ \\
\hline$\overline{\mathbf{A}}$ & $\mathrm{T}_{\mathrm{A}} \mathrm{S}_{1}$ & & $\begin{array}{c}\mathrm{T}_{\mathrm{A}} \mathrm{S}_{2} \\
\mathrm{~V}\end{array}$ & & $\begin{array}{c}\mathrm{T}_{\mathrm{A}} \mathrm{S}_{3} \\
\mathrm{~V}\end{array}$ \\
\hline B & $\mathrm{T}_{\mathrm{B}} \mathrm{S}_{1}$ & $\mathrm{H}_{1,1}$ & $\begin{array}{c}\mathrm{T}_{\mathrm{B}} \mathrm{S}_{2} \\
\mathrm{~V}_{2,2}\end{array}$ & $\mathrm{H}_{1,2}$ & $\begin{array}{c}\mathrm{T}_{\mathrm{B}} \mathrm{S}_{3} \\
\mathrm{~V}_{2,3}\end{array}$ \\
\hline C & $\mathrm{TcS}_{1}$ & $\mathrm{H}_{2,1}$ & $\begin{array}{l}\mathrm{TcS}_{2} \\
\mathrm{~V}_{3,2}\end{array}$ & $\mathrm{H}_{2,2}$ & $\begin{array}{l}\mathrm{TcS}_{3} \\
\mathrm{~V}_{3,3}\end{array}$ \\
\hline D & $\mathrm{T}_{\mathrm{D}} \mathrm{S}_{1}$ & $\mathrm{H}_{3,1}$ & $\mathrm{~T}_{\mathrm{D}} \mathrm{S}_{2}$ & $\mathrm{H}_{3,2}$ & $\mathrm{~T}_{\mathrm{D}} \mathrm{S}_{3}$ \\
\hline
\end{tabular}

Where $\mathrm{H}_{\mathrm{n}, \mathrm{m}}$ : The holding time of product in stages

Table 3. The process data of Example 1

\begin{tabular}{ccccc}
\hline \multirow{2}{*}{ Products } & \multicolumn{4}{c}{ Unit ( Processing time ), hr } \\
\cline { 2 - 5 } & $\mathbf{S}_{\mathbf{1}}$ & $\mathbf{S}_{\mathbf{2}}$ & $\mathbf{S}_{\mathbf{3}}$ & $\mathbf{S}_{\mathbf{4}}$ \\
\hline $\mathbf{P}_{\mathbf{1}}$ & 14 & 45 & 49 & 37 \\
$\mathbf{P}_{\mathbf{2}}$ & 36 & 12 & 39 & 46 \\
$\mathbf{P}_{\mathbf{3}}$ & 29 & 35 & 50 & 30 \\
$\mathbf{P}_{\mathbf{4}}$ & 45 & 30 & 19 & 20 \\
\hline
\end{tabular}

Table 4. The idle time between stages of Example 1

\begin{tabular}{ccccc}
\hline \multirow{2}{*}{ Product } & \multicolumn{4}{c}{ Unit ( Processing time), $\mathbf{h r}$} \\
\cline { 2 - 5 } & $\mathbf{S}_{\mathbf{1}}$ & $\mathbf{S}_{\mathbf{2}}$ & $\mathbf{S}_{\mathbf{3}}$ & $\mathbf{S}_{\mathbf{4}}$ \\
\hline $\mathbf{P}_{\mathbf{1}}$ and $\mathbf{P}_{\mathbf{2}}$ & 46 & 37 & 0 & 2 \\
$\mathbf{P}_{\mathbf{2}}$ and $\mathbf{P}_{\mathbf{3}}$ & 0 & 17 & 13 & 17 \\
$\mathbf{P}_{\mathbf{3}}$ and $\mathbf{P}_{\mathbf{4}}$ & 21 & 31 & 11 & 0 \\
\hline
\end{tabular}

Table 5. Computational results for all production sequences:

\begin{tabular}{cc}
\hline Production sequence & Makespan, $\mathbf{h r}$ \\
\hline $\mathrm{P}_{1} \mathrm{P}_{2} \mathrm{P}_{3} \mathrm{P}_{4}$ & 260 \\
$\mathrm{P}_{1} \mathrm{P}_{2} \mathrm{P}_{4} \mathrm{P}_{3}$ & 289 \\
$\mathrm{P}_{1} \mathrm{P}_{4} \mathrm{P}_{2} \mathrm{P}_{3}$ & 277 \\
$\mathrm{P}_{1} \mathrm{P}_{4} \mathrm{P}_{3} \mathrm{P}_{2}$ & 296 \\
$\mathrm{P}_{1} \mathrm{P}_{3} \mathrm{P}_{4} \mathrm{P}_{2}$ & 273 \\
$\mathrm{P}_{1} \mathrm{P}_{3} \mathrm{P}_{2} \mathrm{P}_{4}$ & 263 \\
$\mathrm{P}_{2} \mathrm{P}_{3} \mathrm{P}_{1} \mathrm{P}_{4}$ & 256 \\
$\mathrm{P}_{2} \mathrm{P}_{3} \mathrm{P}_{4} \mathrm{P}_{1}$ & 292 \\
$\mathrm{P}_{2} \mathrm{P}_{4} \mathrm{P}_{3} \mathrm{P}_{1}$ & 285 \\
$\mathrm{P}_{2} \mathrm{P}_{4} \mathrm{P}_{1} \mathrm{P}_{3}$ & 288 \\
$\mathrm{P}_{2} \mathrm{P}_{1} \mathrm{P}_{3} \mathrm{P}_{4}$ & 244 \\
$\mathrm{P}_{2} \mathrm{P}_{1} \mathrm{P}_{4} \mathrm{P}_{3}$ & 277 \\
$\mathrm{P}_{3} \mathrm{P}_{1} \mathrm{P}_{2} \mathrm{P}_{4}$ & 268 \\
$\mathrm{P}_{3} \mathrm{P}_{1} \mathrm{P}_{4} \mathrm{P}_{2}$ & 285 \\
\hline
\end{tabular}




\begin{tabular}{cc}
\hline Production sequence & Makespan, $\mathbf{h r}$ \\
\hline $\mathrm{P}_{3} \mathrm{P}_{4} \mathrm{P}_{1} \mathrm{P}_{2}$ & 304 \\
$\mathrm{P}_{3} \mathrm{P}_{4} \mathrm{P}_{2} \mathrm{P}_{1}$ & 277 \\
$\mathrm{P}_{3} \mathrm{P}_{2} \mathrm{P}_{1} \mathrm{P}_{4}$ & 267 \\
$\mathrm{P}_{3} \mathrm{P}_{2} \mathrm{P}_{4} \mathrm{P}_{1}$ & 311 \\
$\mathrm{P}_{4} \mathrm{P}_{2} \mathrm{P}_{1} \mathrm{P}_{3}$ & 270 \\
$\mathrm{P}_{4} \mathrm{P}_{2} \mathrm{P}_{3} \mathrm{P}_{1}$ & 282 \\
$\mathrm{P}_{4} \mathrm{P}_{3} \mathrm{P}_{1} \mathrm{P}_{2}$ & 294 \\
$\mathrm{P}_{4} \mathrm{P}_{3} \mathrm{P}_{2} \mathrm{P}_{1}$ & 293 \\
$\mathrm{P}_{4} \mathrm{P}_{1} \mathrm{P}_{2} \mathrm{P}_{3}$ & 301 \\
$\mathrm{P}_{4} \mathrm{P}_{1} \mathrm{P}_{3} \mathrm{P}_{2}$ & 304 \\
\hline
\end{tabular}

The summary of results of the proposed method is shown in table 5 for scheduling four products which indicates $\mathrm{P}_{2} \mathrm{P}_{1} \mathrm{P}_{3} \mathrm{P}_{4}$ was the optimal production sequence according to minimum value of makespan with value $244 \mathrm{hr}$.

Table 6. The idle time between stages for optimal sequence $\left(\mathbf{P}_{2}-\mathbf{P}_{1}-\mathbf{P}_{3}-\mathbf{P}_{4}\right)$ of Example 1

\begin{tabular}{cccccc}
\hline \multirow{2}{*}{ Product } & \multicolumn{4}{c}{ Unit ( Processing time ), hr } \\
\cline { 2 - 5 } & $\mathbf{S}_{\mathbf{1}}$ & $\mathbf{S}_{\mathbf{2}}$ & $\mathbf{S}_{\mathbf{3}}$ & $\mathbf{S}_{\mathbf{4}}$ \\
\hline $\mathbf{P}_{\mathbf{1}}$ and $\mathbf{P}_{\mathbf{2}}$ & 0 & 2 & 8 & 11 \\
$\mathbf{P}_{\mathbf{2}}$ and $\mathbf{P}_{\mathbf{3}}$ & 30 & 14 & 0 & 13 \\
$\mathbf{P}_{\mathbf{3}}$ and $\mathbf{P}_{\mathbf{4}}$ & 21 & 31 & 11 & 0 \\
\hline
\end{tabular}

Table 7. Comparison of results for Example 1

\begin{tabular}{lcc}
\hline & Ming et al [ 16 ] & Present work \\
\hline & HPDE & Matrix approach \\
Method & ( Hybrid & using Java Computer \\
& permutation & programming \\
differential & language \\
& evolution) & \\
Feasible sequence & $\mathrm{P}_{1} \mathrm{P}_{2} \mathrm{P}_{3} \mathrm{P}_{4}$ & $\mathrm{P}_{1} \mathrm{P}_{2} \mathrm{P}_{3} \mathrm{P}_{4}$ \\
Makespan ( hr) & $260 \mathrm{hr}$ & $260 \mathrm{hr}$ \\
Optimal sequence & $\mathrm{P}_{2} \mathrm{P}_{1} \mathrm{P}_{3} \mathrm{P}_{4}$ & $\mathrm{P}_{2} \mathrm{P}_{1} \mathrm{P}_{3} \mathrm{P}_{4}$ \\
Makespan (hr) & $244 \mathrm{hr}$ & $244 \mathrm{hr}$ \\
\hline
\end{tabular}

The summary of results of the proposed method is shown in table 7 along with those of Ming et al [16] where the total completion time (makespan ) using HPDE of feasible production sequence $\left(\mathrm{P}_{1} \mathrm{P}_{2} \mathrm{P}_{3} \mathrm{P}_{4}\right)$ with value $260 \mathrm{hr}$ and the optimal production sequence $\left(\mathrm{P}_{2} \mathrm{P}_{1} \mathrm{P}_{3} \mathrm{P}_{4}\right)$ with value $244 \mathrm{hr}$ which confirmed with results obtained and ensures our strategy.

Table 8. The process data of Example 2

\begin{tabular}{ccccc}
\hline \multirow{2}{*}{ Products } & \multicolumn{4}{c}{ Unit ( Processing time ), hr } \\
\cline { 2 - 5 } & $\mathbf{S}_{\mathbf{1}}$ & $\mathbf{S}_{\mathbf{2}}$ & $\mathbf{S}_{\mathbf{3}}$ & $\mathbf{S}_{\mathbf{4}}$ \\
\hline $\mathbf{A}$ & 10 & 20 & 5 & 30 \\
$\mathbf{B}$ & 15 & 8 & 12 & 10 \\
$\mathbf{C}$ & 20 & 7 & 9 & 5 \\
$\mathbf{D}$ & 14 & 6 & 15 & 10 \\
$\mathbf{E}$ & 6 & 11 & 5 & 15 \\
F & 13 & 7 & 17 & 10 \\
\hline
\end{tabular}

Table 9. The idle time between stages of Example 2

\begin{tabular}{l|cccc}
\hline \multirow{2}{*}{ Product } & \multicolumn{4}{c}{ Unit (Processing time), hr } \\
\cline { 2 - 5 } & $\mathbf{S}_{\mathbf{1}}$ & $\mathbf{S}_{\mathbf{2}}$ & $\mathbf{S}_{\mathbf{3}}$ & $\mathbf{S}_{\mathbf{4}}$ \\
\hline A and B & 0 & 4 & 7 & 4 \\
B and C & 0 & 6 & 0 & 5 \\
C and D & 0 & 4 & 9 & 4
\end{tabular}

\begin{tabular}{cccccc}
\hline \multirow{2}{*}{ Product } & \multicolumn{4}{c}{ Unit ( Processing time ), hr } \\
\cline { 2 - 5 } & $\mathbf{S}_{\mathbf{1}}$ & $\mathbf{S}_{\mathbf{2}}$ & $\mathbf{S}_{\mathbf{3}}$ & $\mathbf{S}_{\mathbf{4}}$ \\
\hline D and E & 18 & 11 & 13 & 0 \\
E and F & 0 & 13 & 3 & 2 \\
\hline
\end{tabular}

Table 10. Summary of computational results of production sequences

\begin{tabular}{c|c|c|c}
\hline $\begin{array}{c}\text { Feasible } \\
\text { sequence }\end{array}$ & $\begin{array}{c}\text { Makespan } \\
\text { (hr) }\end{array}$ & $\begin{array}{c}\text { Optimal } \\
\text { sequence }\end{array}$ & $\begin{array}{c}\text { Makespan } \\
\text { (hr) }\end{array}$ \\
\hline & & E-D-B-A-F-C & $117 \mathrm{hr}$ \\
A-B-C-D-E-F & $141 \mathrm{hr}$ & $\begin{array}{c}\text { E-B-D-A-F-C } \\
\text { p-B }\end{array}$ & \\
\hline
\end{tabular}

The summary of computational results of the proposed method is shown in table 10 which indicates two optimal production sequence according to minimum value of makespan with value $117 \mathrm{hr}$. for production sequence ( E-D-B-A-F-C) and the proposed method indicates another optimal production sequence (E-D-B-A-F-C) according to makespan value117 hr. due to the total processing time of products B \& D was the same in all stages and in table 11 and 12 represented the idle times between stages for two optimal production sequences. Also, (Fig.6) and (Fig.7) showed the Gantt chart for these sequences.

Table 11. The idle time between stages for optimal sequence no. 1

\begin{tabular}{l|cccc}
\hline Product & \multicolumn{4}{c}{ Unit ( Processing time ), hr } \\
& $\mathbf{S}_{\mathbf{1}}$ & $\mathbf{S}_{\mathbf{2}}$ & $\mathbf{S}_{\mathbf{3}}$ & $\mathbf{S}_{\mathbf{4}}$ \\
\hline E and B & 0 & 4 & 7 & 4 \\
B and D & 0 & 6 & 0 & 5 \\
D and A & 0 & 4 & 9 & 4 \\
A and F & 18 & 11 & 13 & 0 \\
F and C & 0 & 13 & 3 & 2 \\
\hline
\end{tabular}

Table 12. The idle time between stages for optimal sequence no. 2

\begin{tabular}{c|cccc}
\hline \multirow{2}{*}{ Product } & \multicolumn{4}{c}{ Unit ( Processing time ), hr } \\
\cline { 2 - 5 } & $\mathbf{S}_{\mathbf{1}}$ & $\mathbf{S}_{\mathbf{2}}$ & $\mathbf{S}_{\mathbf{3}}$ & $\mathbf{S}_{\mathbf{4}}$ \\
\hline E and D & 0 & 3 & 4 & 4 \\
D and B & 0 & 9 & 2 & 4 \\
B and A & 0 & 2 & 10 & 5 \\
A and F & 18 & 11 & 13 & 0 \\
F and C & 0 & 13 & 3 & 2 \\
\hline
\end{tabular}

Table 13. Comparison of results for example 2.

\begin{tabular}{|c|c|c|}
\hline & D.B.Birewar et al, [2] & Present work \\
\hline Method & $\begin{array}{l}\text { Mixed Integer } \\
\text { Linear } \\
\text { Programming } \\
\text { (MILP) }\end{array}$ & $\begin{array}{c}\text { Matrix approach } \\
\text { using Java } \\
\text { Computer } \\
\text { programming } \\
\text { Language }\end{array}$ \\
\hline Feasible sequence & A-B-C-D-E-F & A-B-C-D-E-F \\
\hline Makespan ( hr) & 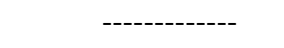 & $141 \mathrm{hr}$. \\
\hline Optimal sequence & E-B-D-A-F-C & $\begin{array}{l}\text { E-B-D-A-F-C } \\
\text { E-D-B-A-F-C }\end{array}$ \\
\hline Makespan (hr) & $117 \mathrm{hr}$. & $117 \mathrm{hr}$. \\
\hline
\end{tabular}

The summary of results of the proposed method is shown in table 13, along with those of D.B.Birewar et al, [2] where the total completion time (makespan ) using MILP of feasible production sequence (A-B-C-D-E-F) with value $141 \mathrm{hr}$ and the optimal production sequence (E-B-D-A-F-C) with value 117 
hr. and the proposed method indicates another optimal production sequence (E-D-B-A-F-C) according to makespan value $117 \mathrm{hr}$. thus gives more flexibility to our proposed method than Mixed Integer Linear Programming (MILP) method which used by D.B.Birewar et al, [2] , at which confirmed with results obtained and which ensures our strategy.

Table1 14. The process data of Example 3

\begin{tabular}{ccccccc}
\hline \multirow{2}{*}{ Products } & \multicolumn{6}{c}{ Unit ( Processing time ), hr } \\
\cline { 2 - 7 } & $\mathbf{S}_{\mathbf{1}}$ & $\mathbf{S}_{\mathbf{2}}$ & $\mathbf{S}_{\mathbf{3}}$ & $\mathbf{S}_{\mathbf{4}}$ & $\mathbf{S}_{\mathbf{5}}$ & $\mathbf{S}_{\mathbf{6}}$ \\
\hline $\mathbf{A}$ & 10 & 15 & 20 & 12 & 8 & 11 \\
B & 15 & 8 & 12 & 10 & 9 & 13 \\
C & 10 & 22 & 9 & 5 & 6 & 9 \\
D & 20 & 12 & 7 & 10 & 10 & 4 \\
\hline
\end{tabular}

Table 15. Computational results for all production sequences

\begin{tabular}{cc}
\hline Production sequence & Makespan, hr. \\
\hline ABCD & 110 \\
ABDC & 108 \\
ADBC & 110 \\
ADCB & 120 \\
ACDB & 114 \\
ACBD & 110 \\
BCAD & 118 \\
BCDA & 125 \\
BDCA & 135 \\
BDAC & 123 \\
BACD & 105 \\
BADC & 111 \\
CABD & 115 \\
CADB & 123 \\
CDAB & 123 \\
CDBA & 123 \\
CBAD & 113 \\
CBDA & 130 \\
DBAC & 120 \\
DBCA & 133 \\
DCAB & 133 \\
DCBA & 130 \\
DABC & 120 \\
DACB & 123 \\
\hline
\end{tabular}

The summary of results of the proposed method is shown in table 15 where makespan of feasible production sequence (A$\mathrm{B}-\mathrm{C}-\mathrm{D})$ with value $110 \mathrm{hr}$. and the optimal production sequence (B-A-C-D) with value $105 \mathrm{hr}$. which confirmed with results obtained and ensures our strategy.

\section{CONCLUSION}

The present study presents scheduling of flowshop batch process with zero-wait (ZW) and No Intermediate Storage (NIS) transfer policy using computer programming language Java software which simplified and determine total completion time (makespan) for all possible sequences and the optimal sequence due to its minimum makespan for scheduling of multi-product batch process. The proposed software when applied to problems previously reported in the literature yielded optimum sequences which are consistent with different approach used. It is evident that the performance of the software is quite encouraging, characterized by its simplicity and implementation for any numbers of products in batch processes which can be difficult by using of hand calculations.
The results of case studies show that the present software is accurate in finding makespan and estimate the optimal production sequence in comparison with previous works.

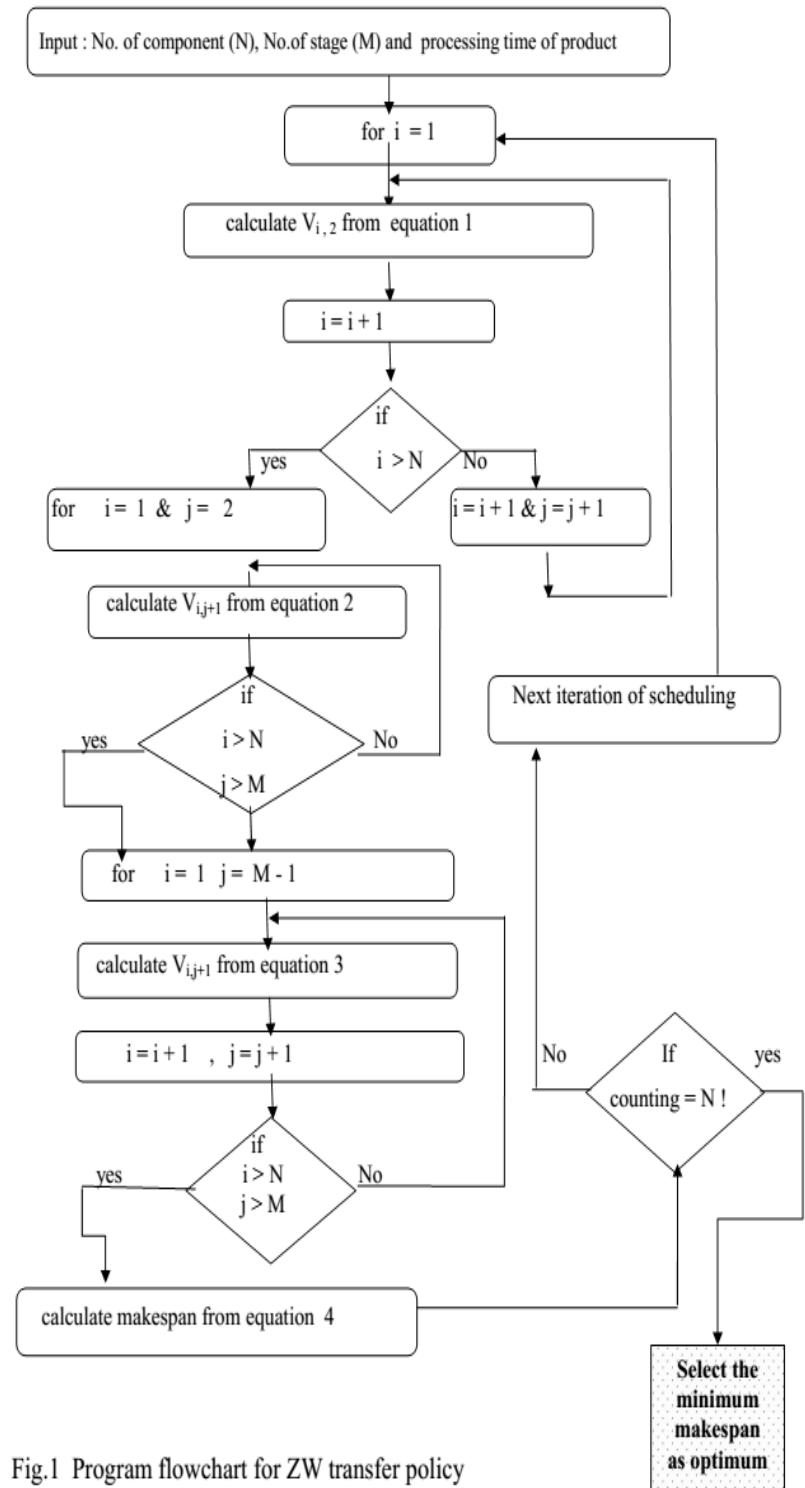




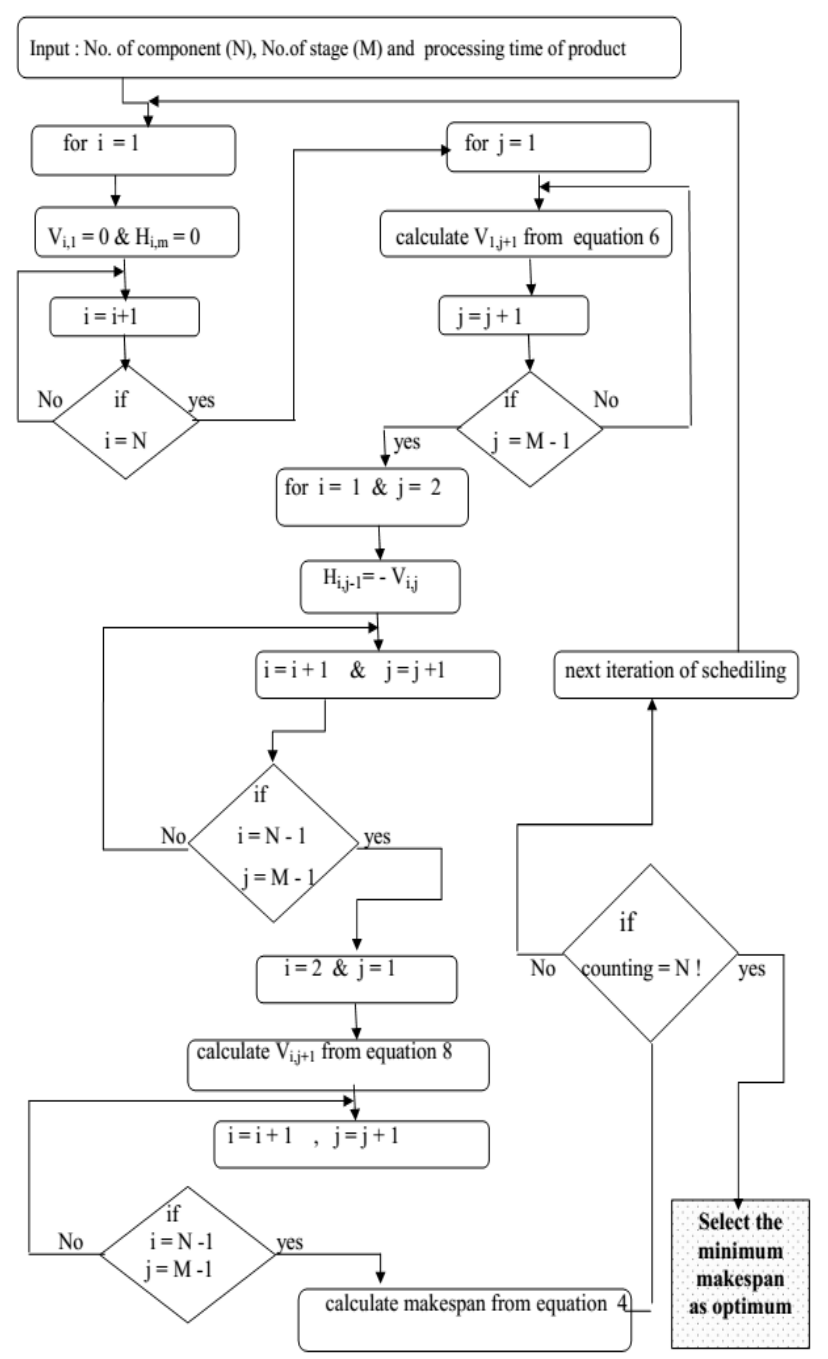

Fig.2 Program flowchart for NIS transfer policy



Fig.3 Gantt chart of example 1 for feasible sequence $\left(\mathbf{P}_{1}-\mathbf{P}_{2}-\mathbf{P}_{3}-\mathbf{P}_{4}\right)$ with makespan $260 \mathrm{hr}$

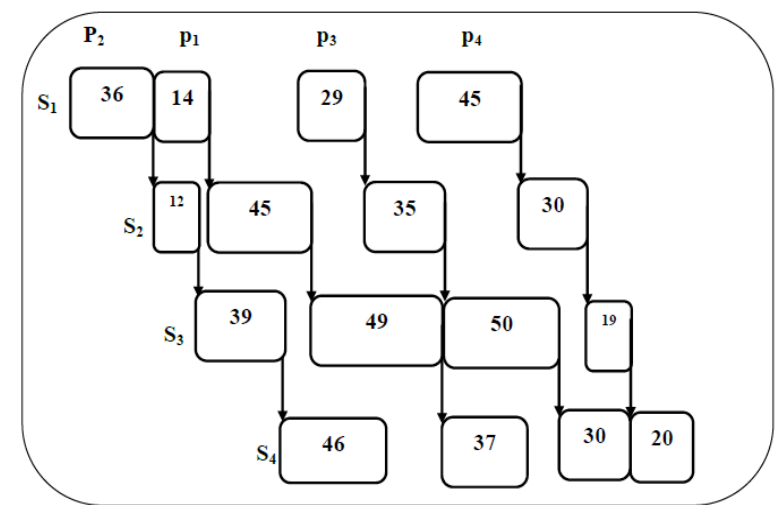

Fig.4 Gantt chart of example 1 for optimal sequence $\left(\mathbf{P}_{2}-\mathbf{P}_{1}-\mathbf{P}_{3}-\mathbf{P}_{4}\right)$ with makespan $244 \mathrm{hr}$

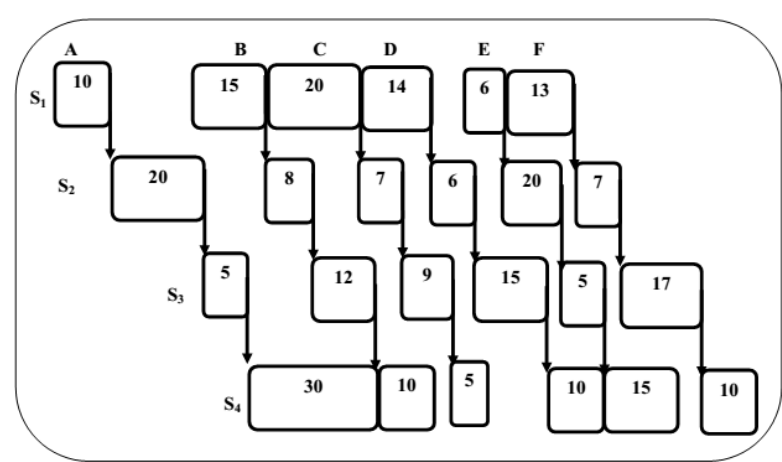

Fig.5 Gantt chart of example 2 for feasible sequence (A-B-C-D-E-F) with makespan $144 \mathrm{hr}$

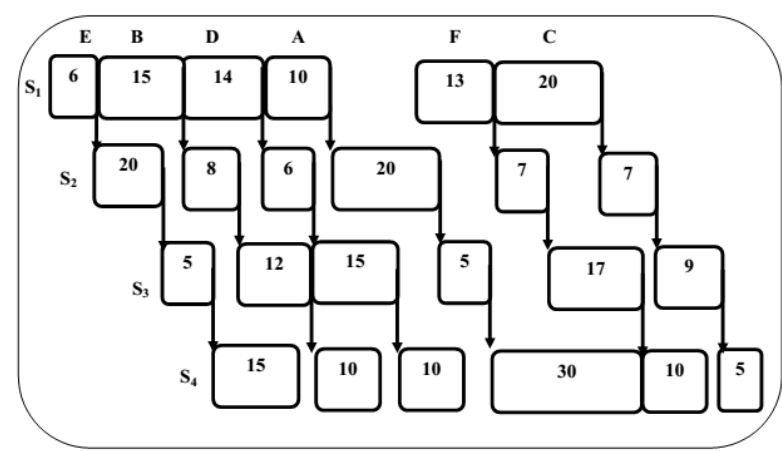

Fig.6 Gantt chart of example 2 for optimal sequence (E-B-D-A-F-C) with makespan $117 \mathrm{hr}$

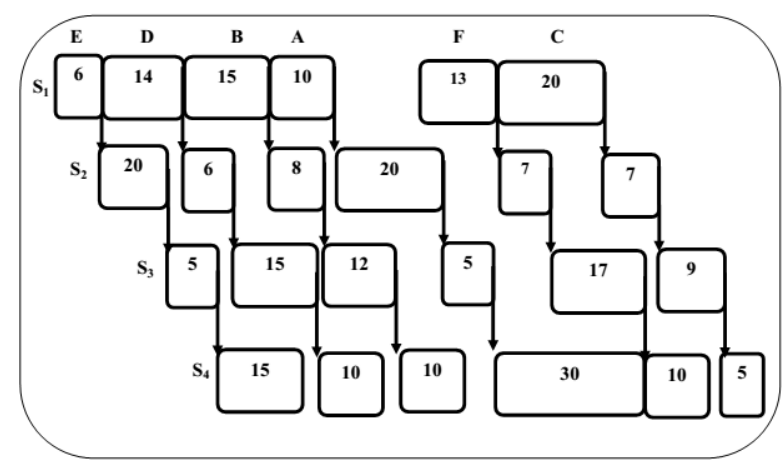

Fig.7 Gantt chart of example 2 for optimal sequence (E-D-B-A-F-C) with makespan $117 \mathrm{hr}$ 




Fig.8 Gantt chart of example 3 for feasible sequence (A-B -C-D with makespan $110 \mathrm{hr}$

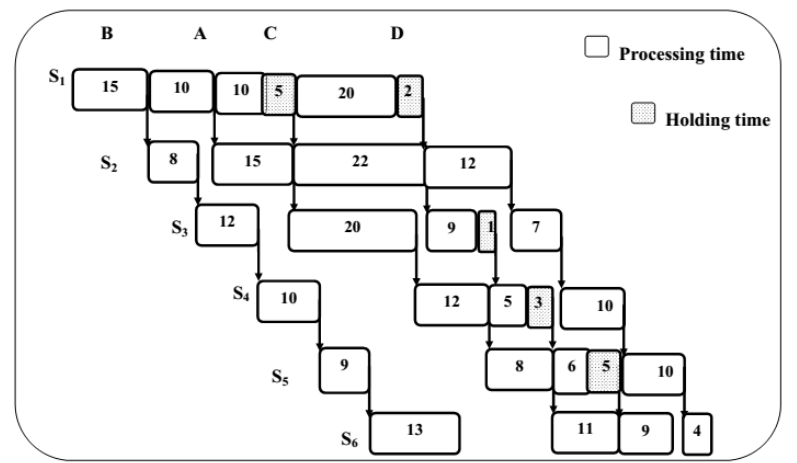

Fig.9 Gantt chart of example 3 for optimal sequence (B-A-C-D) with makespan $105 \mathrm{hr}$

\section{Nomenclature}

$\begin{array}{ll}\text { ZW } & \text { Zero Wait } \\ \text { NIS } & \text { Non Intermediate Storage } \\ \text { ZWSP } & \text { Zero Wait Scheduling Problem } \\ \text { MINLP } & \text { Mixed Integer Non Linear Programming } \\ \text { MILP } & \text { Mixed Integer Linear Programming } \\ \text { HPDE } & \text { Hybrid Permutation Differential Evolution }\end{array}$

\section{REFERENCES}

[1] Biegler, L.T., Grossmann, I.E. and Westberg, A.W., (1997).Systematic Methods of Chemical Process Design. (Prentice-Hall).

[2] Birewar, D.B. and Grossmann, I.E., 1989, "Efficient optimization algorithms for zero-wait scheduling of multiproduct batch plants". Ind Eng Chem Res, 28(9): 1333-1345.

[3] Burkard, R.E., Fortuna, T.C. and Hurkens, A.J., 2002, "Makespan minimization for chemical batch processes using non-uniform time grids". Comput Chem Eng, 26(9): $1321-1332$.
[4] Das, H., Cummings, P.T. and Le Van, M.D., 1990, "Scheduling of serial multiproduct batch processes via simulated annealing". Comput Chem Eng, 14(12): 13511362.

[5] Dupont, L. and Dhaenens-Flipo, C., 2002," Minimizing the makespan on a batch machine with non-identical job sizes: an exact procedure". Comp Oper Res, 29: 807-819.

[6] Edgar, T.F., Himmelblau, D.M. and Lasdon, L.S., (2001). Optimization of Chemical Processes (2nd edition). (McGraw Hill).

[7] Grossmann, I. and Morari, M., Morari, M. (eds). (CACHE Corporation, Austin, TX)

[8] Jung, J., Lee, H., Yang, D. and Lee, I., 1994, "Completion times and optimal scheduling for serial multi-product processes with transfer and set-up times in zero-wait policy". Comput Chem Eng, 18(6): 537-544.

[9] Jun-Hyung Ryu and Efstratios N. Pistikopoulos (2007) "A novel approach to scheduling of zero wait batch processes under processing time variations". Computers and Chemical Engineering, 31: 101-106.

[10] Kim, M., Jung, J.H. and Lee, I.B., 1996, "Optimal scheduling of multiproduct batch processes for various intermediate storage policies". Ind Eng Chem Res, 35(11): 4058-4066.

[11] Ku, H.M. and Karimi, I.A., 1988," Scheduling in serial multiproduct batch processes with finite interstage storage: a mixed integer linear program formulation". Ind Eng Chem Res, 27(10):1840-1848.

[12] Ku, H.M. and Karimi, I.A., 1990, "Completion time algorithms for serial multiproduct batch processes with shared storage". Comput Chem Eng, 14(1): 49-69.

[13] Ku, H.M. and Karimi, I.A., 1992, Multiproduct batch plant scheduling, in CACHE Process Design Case Studies,

[14] L. Dupont and C. Dhaenens-Flipo (2002) "Minimizing the makespan on a batch machine with non-identical job sizes: an exact procedure". Computers and Operations Research, 29: 807-819.

[15] Lee, D.S., Vassiliadis Vassilios, S. and Park, J.M., 2002, "List-based threshold-accepting algorithm for zero-wait scheduling of multiproduct batch plants". Ind Eng Chem Res, 41(25): 6579-6588.

[16] Ming-Gang Dong and Ning Wang (2012), "A novel hybrid differential evolution approach to scheduling of large scale zero wait batch process with setup times". Comput Chem Eng, 45:72-83.

[17] Moon, S., Park, S. and Lee, W.K., 1996, "New MILP models for scheduling of multiproduct batch plants under zero-wait policy". Ind Eng Chem Res, 35(10): 3458-3469. 